\title{
Broadening the chemical coverage to derive human toxicity dose-response factors for non-cancer endpoints
}

\author{
Aurisano, Nicolo; Huang, L.; Jang, Suji; Chiu, W.A.; Judson, Richard S. ; Jolliet, Olivier; Fantke, Peter
}

Publication date:

2021

Document Version

Publisher's PDF, also known as Version of record

Link back to DTU Orbit

Citation (APA):

Aurisano, N., Huang, L., Jang, S., Chiu, W. A., Judson, R. S., Jolliet, O., \& Fantke, P. (2021). Broadening the chemical coverage to derive human toxicity dose-response factors for non-cancer endpoints. S241-S241. Abstract from 56 th Congress of the European Societies of Toxicology.

\section{General rights}

Copyright and moral rights for the publications made accessible in the public portal are retained by the authors and/or other copyright owners and it is a condition of accessing publications that users recognise and abide by the legal requirements associated with these rights.

- Users may download and print one copy of any publication from the public portal for the purpose of private study or research.

- You may not further distribute the material or use it for any profit-making activity or commercial gain

- You may freely distribute the URL identifying the publication in the public portal 
P25-15

\section{Toxicokinetic interactions of industrial chemical mixtures} as internal exposure modifiers

${ }^{*}$ S. Karakitsios ${ }^{1,2}$, I.Petridis ${ }^{1}$, V. Kokaraki ${ }^{3}$, D. Sarigiannis ${ }^{1,2,3}$

1 Aristotle University of Thessaloniki, Chemical Engineering-EnvE Lab, Thessaloniki, Greece;

2 Center for Interdisciplinary Research and Innovation, Aristotle University of Thessaloniki, HERACLES Research Center on the Exposome and Health, Thessaloniki, Greece;

3 School for Advanced Study (IUSS), Science, Technology and Society Department, Pavia, Italy

Single chemical exposure is an exception rather than the rule in the general and occupational environments. The risk assessment of chemical mixtures is particularly challenging due to the number of chemicals combined, limited knowledge on composition, the toxicokinetics and toxicodynamics of components. For this study thee relevant mixtures of chemicals were investigated. The first one is the bisphenols' mixtures consisting of bisphenol $\mathrm{A}, \mathrm{S}$ and $\mathrm{F}$, the second one is the phthalates' mixture consisting of DEHP, BBzP, DnBP and DiNP and the third one of BTEX (benzene, ethylbenzene, toluene and xylene). In order to evaluate the inhibitory effect on the metabolism as a result of co-exposure, a broad range of mean daily intake levels (bodyweight normalised) have been tested for bisphenols and phthalates, starting from $0.01 \mu \mathrm{g} / \mathrm{kg}$ bw/day up to $100,000 \mu \mathrm{g} / \mathrm{kg}$ bw/day., while for the BTEX, the TLV's for the four chemicals considered here are (a) benzene $0.5 \mathrm{ppm}$ (b) toluene $33.0 \mathrm{ppm}$ (c) xylenes $50.0 \mathrm{ppm}$ (d) ethylbenzene $50.0 \mathrm{ppm}$ have been used. From the results of the coexposure interaction, it was clearly shown that under environmentally relevant exposure levels and even at the level of EFSA's temporary tolerable daily intake (tTDI) of $4 \mu \mathrm{g} / \mathrm{kg}$ bw/d for bisphenol A and $50 \mu \mathrm{g} / \mathrm{kg}$ _bw/d for DEHP, the effect of interaction on the internal dose (expressed as increase of the Area Under Curve, AUC) is negligible (below 1\%). However, as expected, the interaction effect is higher when the daily intake level increases. The interaction is significant for intake levels above $10,000 \mu \mathrm{g} / \mathrm{kg}$ bw/d, which might be relevant only for occupational settings. Similarly, for BTEX, the changes in internal dose upon inhalation exposure are dose dependent, and they become more evident as we move closer to the TLV.

From all the case studies, it is evident that co-exposure to chemicals that are subjected to interaction at the level of metabolism, is crucial at high exposure levels, that are mostly met in occupational settings. Thus, although in environmentally relevant exposure levels, interactions at the level of metabolism regarding cumulative exposure might not be a major concern, they have to be taken into account when estimating or apply the exposure-response relationships. Hense, these results indicate, that a broader framework of interactions that affect bioavailability upon cumulative exposure might need to be investigated, as well as integration of toxicokinetic and toxicodynamic models (and more specifically biology based dose response models); in our view this has to be the next step in cumulative exposure risk assessment, and qAOPs (quantitative adverse outcome pathways) seem to be the ideal substrate towards this direction.

\section{P26 - Toxicology in life cycle analysis}

\section{P26-01}

\section{Broadening the chemical coverage to derive human} toxicity dose-response factors for non-cancer endpoints

${ }^{*}$ N. Aurisano ${ }^{1}$, L. Huang ${ }^{2}$, S. Jang ${ }^{3}$, W.A.Chiu ${ }^{3}$, R.Judson ${ }^{4}$, O. Jolliet $^{2}$, P.Fantke ${ }^{1}$

1 Technical University of Denmark, Quantitative Sustainability Assessment, Department of Technology, Management and Economics, Kgs. Lyngby, Denmark;

2 University of Michigan, Department of Environmental Health Sciences, Ann Arbor, USA;

3 Texas AEM University, Department of Veterinary Integrative Biosciences, College of Veterinary Medicine and Biomedical Sciences, College Station, USA;

4 U.S. Environmental Protection Agency, National Center for Computational Toxicology, Research Triangle Park, USA

When assessing impacts of chemical life cycle emissions and of chemicals in products on human health, chemical-specific points of departure (PODs) are crucial to derive toxicity-related effect factors. Recent updates of the globally recommended approach for deriving human dose-response factors for non-cancer endpoints in life cycle impact assessment (LCIA) proposes prioritizing the usage of regulatory assessment-based PODs. Such data are available only for several hundreds of chemicals and are missing for the wider range of currently marketed chemicals. As an alternative, experimental animal data can be used to estimate PODs that most closely mimic one that would be selected in a regulatory assessment context. The aim of this study is thus to use available in vivo data to estimate suitable PODs for substances lacking regulatory assessments in order to broaden the coverage of chemicals for application in LCIA. As a first step, we extracted experimental animal data available from the US EPA ToxValDB, focusing on oral repeated-dose studies and three non-cancer effect-level types: lowest observed adverse effect level (LOAEL), noobserved adverse effect level (NOAEL) and benchmark dose lower bound (BMDL). The extracted dataset needed further curation before use in LCIA applications, the main steps of which included harmonization of the reported test species names, conversion of units to $\mathrm{mg} /$ $\mathrm{kg}-\mathrm{d}$, as well as different extrapolations from subchronic or subacute studies to chronic, from the other effect-level types to benchmark dose (BMD) and from tested animal species to humans. After curation, for each chemical with at least 10 studies, we fit the resulting data to a lognormal distribution. For chemicals with less than 10 studies, we fit the distribution while applying a fixed standard deviation of $\log _{10}=0.55$, based on the average standard deviation across data-rich chemicals in our curated dataset. In total, we derived PODs for 8241 chemicals based on the $5^{\text {th }}$ percentile of the fitted lognormal distribution. The resulting $\log _{10}$ POD values ranged by orders of magnitude from $-5.57 \mathrm{mg} / \mathrm{kg}$ - $\mathrm{d}$ to $4.04 \mathrm{mg} / \mathrm{kg}-\mathrm{d}$ across the considered substances, with a median $\log _{10} \mathrm{POD}=0.92 \mathrm{mg} / \mathrm{kg}$-d. For the 749 chemicals having available regulatory PODs, we observed a good correlation with our derived $5^{\text {th }}$ percentile PODs $\left(R^{2}=0.66\right.$ and $R M S E=$ 0.65 of the $\log _{10}$-transformed values). These results suggest that the proposed method is able to derive PODs consistent with regulatory values in a high-throughput manner, thus substantially increasing the coverage of chemical substances for application in LCIA.

This abstract does not necessarily reflect US EPA policy. 